\title{
Supercritical water gasification of empty fruit bunches from oil palm for hydrogen production
}

\begin{abstract}
Empty fruit bunches (EFBs) from the palm plantation sector are abundant agricultural waste products in Malaysia. Supercritical water gasification (SCWG) is a prominent way to convert high-moisture-content biomass such as EFBs into valuable end products. This investigation is focused on EFB conversion into hydrogen-rich products using SCWG (temperature $=380{ }^{\circ} \mathrm{C}$ and pressure $\approx 240$ bar). Lignocellulosic model compounds (xylan, cellulose, and lignin) were used to study the degradation patterns and gas compositions under similar reaction conditions. The effect of the EFB/water ratio and the SCWG reaction time on the composition of the product gas was examined. Carbon gasification does not improve with increasing EFB/water ratio as well as with increasing reaction time caused by the thermally stable tar formation during reaction. The hydrogen concentration was found to be increased with reaction time along with raising the $\mathrm{EFB} /$ water ratio to $0.3 \mathrm{~g}(3.75 \mathrm{wt} \%)$. In addition, the possibility of using palm oil mill effluent as a reaction medium in comparison to deionized water was analyzed.
\end{abstract}

Keyword: Empty fruit bunches; Palm oil mill effluents; Xylan; Cellulose; Lignin 